\title{
ENTRE POLÍTICAS PÚBLICAS E AÇÕES JUDICIAIS: ATENÇÃO PARA HOMENS AUTORES DE VIOLÊNCIA CONTRA A MULHER NO ESTADO DA BAHIA
}

\author{
BETWEEN PUBLIC POLICIES AND JUDICIAL ACTIONS: ATTENTION TO MEN \\ AUTHORS OF VIOLENCE AGAINST WOMEN IN THE STATE OF BAHIA
}

\begin{abstract}
Resumo
Desde o advento da Lei Maria da Penha, os debates sobre serviços de responsabilização e educação para homens autores de violência contra mulheres têm se intensificado no Brasil. Ainda em número bastante reduzido, tais serviços encontram uma série de dificuldades para se firmar enquanto política nacional específica de enfrentamento à violência contra a mulher, seja pela inexistência de recursos contínuos, seja pelas controvérsias acerca dos desenhos metodológicos que assumem. Neste trabalho, buscamos mapear ações desenvolvidas no interior do estado da Bahia, bem como as repercussões que têm provocado entre os/as gestores/as de políticas públicas. Para tanto, valemo-nos de dados produzidos a partir de entrevistas semiestruturadas e semidiretivas aplicadas com representantes de instituições públicas voltadas ao enfrentamento da violência doméstica e familiar contra a mulher, instaladas em 19 municípios do estado. As entrevistas foram realizadas nos últimos meses de 2015, por ocasião da elaboração do Planejamento Integral Básico (PIB), desenvolvido pela Secretaria de Políticas para as Mulheres do Estado da Bahia, cuja finalidade era sistematizar as ações do Estado para o Pacto de Enfrentamento à Violência contra a Mulher, do qual participamos na condição de pesquisadores. Os resultados apontam para o desenvolvimento de tímidas ações ligadas ao Tribunal de Justiça e alguns atendimentos no âmbito de serviços especializados para as mulheres em situação de violência doméstica e familiar, em total afronta às diretrizes gerais fixadas pela Secretaria de Políticas para as Mulheres da Presidência da República.

Palavras-chave: Violência contra a mulher. Lei Maria da Penha. Políticas públicas. Ações judiciais. Homens autores de violência.
\end{abstract}

Mestre e doutorando pelo Programa de Pós-Graduação em Estudos Interdisciplinares sobre Mulheres, Gênero e Feminismo (PPGNEIM/UFBA).E-mail: Eduardo.carvalho87@yahoo.com.br.

Doutora em Ciências Sociais pela Universidade Federal da Bahia (UFBA). Professora adjunta do curso de Serviço Social e do Programa de Pós-Graduação em Estudos Interdisciplinares sobre Mulheres, Gênero e Feminismo (PPGNEIM) da Universidade Federal da Bahia (UFBA).E-mail: marciatavares1@gmail.com. 


\begin{abstract}
Since the advent of the Maria da Penha Law, debates on accountability and education services for men who have perpetrated violence against women have intensified in Brazil. Even in a very small number, these services face a number of difficulties in establishing themselves as a specific national policy to deal with violence against women, either because of the lack of continuous resources or because of the controversies about the methodological designs they assume. In this work, we seek to map actions developed within the State of Bahia, as well as the repercussions that have provoked among the managers of public policies. To do so, we use data produced from semi-structured and semi-directional interviews with representatives of public institutions aimed at confronting domestic and family violence against women, located in 19 (nineteen) municipalities of the State. The interviews were conducted in the last months of 2015, during the elaboration of Basic Integral Planning - GDP, developed by the Secretariat of Policies for Women of the State of Bahia, whose purpose was to systematize State actions for the Pact to Combat Violence against the Woman, of which we participate in the condition of researchers. The results point to the development of timid actions related to the Court of Justice and some services in specialized services for women in situations of domestic and family violence, in total confronts with the general guidelines set by the Secretariat for Women's Policies of the Presidency of the Republic.
\end{abstract}

Keywords: Violence against women. Maria da Penha Law. Public policy. Judicial actions. Men authors of violence.

\title{
INTRODUÇÃO
}

Após forte pressão dos movimentos feministas e de mulheres, bem como em atendimento à determinação da Comissão Interamericana de Direitos Humanos da Organização dos Estados Americanos (OEA), o Estado brasileiro promulgou a Lei $\mathrm{n}^{\circ} 11.340$, em 7 de agosto de 2006, garantindo um tratamento diferenciado para os crimes que configuram violência doméstica e familiar contra a mulher e descortinando a leniência estatal em relação a tal fenômeno ao promover o recrudescimento da punição de seus autores, consubstanciado, sobretudo, na proibição de penas exclusivamente pecuniárias e demais institutos despenalizadores previstos na Lei ${ }^{0}$ 9.099/95.

Ademais, a Lei Maria da Penha, como ficou amplamente reconhecida, prevê, em seu artigo 35, a implementação de uma rede de enfrentamento à violência doméstica e familiar contra a mulher composta, dentre outros serviços, por centros de atendimento integral e multidisciplinar e casas-abrigos para as mulheres e seus respectivos dependentes; delegacias, núcleos de defensoria pública, serviços de saúde e centros de perícia médico-legais especializados; programas e campanhas de enfrentamento à violência doméstica e familiar; e "centros de educação e reabilitação para os agressores".

No entanto, não obstante a Lei Maria da Penha reconhecer estratégias de enfrentamento à violência doméstica e familiar que rompem com certos 
pares dicotômicos como vitimização/culpabilização ou mesmo proteção/punição, remetendo-se ao caráter relacional do conceito de gênero, os serviços de responsabilização e educação para homens autores de violência esbarram em uma série de entraves quando se pensa na sua efetiva implementação. Isso porque, nos dizeres de Diniz (2006, p. 40), o tema do atendimento a esses sujeitos tem se configurado como uma "agenda oculta" dos movimentos feministas e de mulheres, por existir "um pressuposto, mais ou menos implícito, de que atender os agressores seja uma substituição para a penalização da violência, um reforço para a impunidade, uma relativização de que a violência contra a mulher é um crime".

No presente trabalho, nossa preocupação se volta a pensar a implementação dos serviços de responsabilização e educação para homens autores de violência no estado da Bahia, buscando mapear as ações desenvolvidas e analisar as repercussões que têm provocado entre os (as) gestores (as) de políticas públicas. Para tanto, tomamos por base dados produzidos a partir de entrevistas semiestruturadas e semidiretivas realizadas com representantes de mecanismos públicos voltados ao enfrentamento da violência doméstica e familiar contra a mulher implantados em 19 municípios do estado, espalhados nos mais distintos territórios de identidade. As entrevistas foram realizadas nos últimos meses de 2015, sendo uma em cada município, por ocasião da elaboração do Planejamento Integral Básico (PIB) do Estado para o Pacto pelo Enfrentamento à Violência contra as Mulheres. ${ }^{3}$

$\mathrm{Na}$ Bahia, tal documento foi elaborado pelo Núcleo de Estudos Interdisciplinares sobre a Mulher (NEIM), da Universidade Federal da Bahia (UFBA), a partir de convênio firmado com a Secretária Estadual de Políticas para as $\mathrm{Mu}$ lheres. Uma equipe de pesquisadores foi montada, sendo atribuída para cada um a responsabilidade sobre os dados de um território de identidade. Todos deveriam aplicar o mesmo roteiro, que continha três questões sobre atendimento a homens autores de violência, buscando identificar a existência de ações, a metodologia empregada e a fonte de financiamento.

Os autores deste artigo estiveram envolvidos no referido trabalho na condição de pesquisadores, o que garantiu acesso às respostas dadas pelos/as gestores/as para tais questionamentos. As falas foram então transcritas e interpretadas a luz da análise de conteúdo categorial (BARDIN, 1977), entendida

OPIB consiste em um diagnóstico que deve incluir um estudo sobre o processo das conferências municipais, regionais e estaduais e políticas para as mulheres, bem como uma avaliação sobre as políticas públicas de enfrentamento à violência e uma proposta de planejamento e orçamento em conformidade com o Plano Plurianual do Estado. Assim, o PIB se converte em um elemento indispensável para a implementação do Pacto de Enfrentamento à Violência contra as Mulheres ao permitir uma visão ampliada das prioridades regionais e nacionais, tendo como uma de suas principais finalidades a sistematização e planejamento das ações a serem desenvolvidas pelo Estado. 
como um conjunto de técnicas de análise das comunicações que possibilitam a inferência de conhecimentos a partir de procedimentos sistemáticos e descritivos dos conteúdos das mensagens.

\section{OS SERVIÇOS DE RESPONSABILIZAÇÃO E EDUCAÇÃO PARA HOMENS AUTORES DE VIOLÊNCIA}

Em nossa sociedade, os homens experimentam processos de socialização e sociabilidade notadamente influenciados por uma lógica machista, sexista e misógina, o que tem perpetuado episódios de violência doméstica e familiar contra as mulheres, ao instituir padrões estereotipados de masculinidades marcados por características como agressividade, honra e virilidade.

Neste sentido, os estudos feministas e de gênero adquirem fundamental relevância para o estudo do tema aqui abordado. Pois, seguindo a linha argumentativa de Joan Scott, gênero pode ser entendido como uma categoria analítica que reconhece as diferenças existentes entre homens e mulheres como socialmente construídas e fundadas a partir de relações de poder, contrapondo-se ao determinismo biológico outrora utilizado para justificá-las. Assim, o uso do conceito de gênero entre feministas norte-americanas, já na década de 1980, indicava, também, uma preocupação com o fato dos estudos feministas estarem centrados nas mulheres de forma estreita e isolada, de modo que se utilizam do termo "gênero" para introduzir uma noção relacional, defendendo que homens e mulheres são definidos em termos recíprocos e nenhuma compreensão pode existir a partir de estudo inteiramente separado. (SCOTT, 1995)

Ademais, ao propor seu projeto de transformação social, os feminismos também possibilitam o desenvolvimento dos estudos sobre homens e masculinidades que, nos últimos anos, mobiliza um número significativo de pesquisadores/as. Desses estudos, destaco o conceito de masculinidade hegemônica defendido por Connell e Messerschmidt (2013), os quais, inspirados pela concepção gramsciniana de "hegemonia", propõem pensá-la como um padrão de práticas que possibilitou a continuidade da dominação dos homens sobre as mulheres. Segundo eles, a masculinidade hegemônica distingue-se das demais, ditas subordinadas, para assumir um caráter normativo, incorporando a forma mais honrada de se reconhecer um homem. Assim, "ela exige que todos os outros homens se posicionem em relação a ela e legitima ideologicamente a subordinação global das mulheres aos homens". (CONNELL; MESSERSCHMIDT, 2013, p. 245)

Essa dominação se expressa, inclusive, na violência masculina contra as mulheres que, desde os idos de 1970, tem sido uma das mais importantes bandei- 
ras de luta dos movimentos feministas e de mulheres no Brasil. Sob o argumento que "o pessoal é político" as ativistas levam ao espaço político de discussão, questões anteriormente tratadas como específicas do privado, rompendo com a dicotomia público/privado do pensamento liberal. (COSTA, 2005) Deste modo, denunciam todas as formas de opressão e submissão experimentadas pelas mulheres no ambiente doméstico, refutando a noção de uma violação individual para inaugurar a tese de que os problemas vivenciados individualmente no cotidiano feminino alicerçavam-se em estruturas e discursos sociais, reivindicando respostas coletivas a partir da formulação e implementação de políticas públicas efetivas. É dizer, os movimentos feministas e de mulheres passam a exercer uma forte pressão para que o Estado incorpore a agenda feminista de enfrentamento à violência doméstica e familiar contra a mulher na política e no Direito.

Os resultados dessas investidas são evidentes. A título meramente ilustrativo, poderíamos apontar a Lei Maria da Penha e toda a rede de proteção e assistência à mulher já enunciada na introdução deste trabalho. Porém, aqui nos interessa a discussão acerca dos serviços de responsabilização e educação para homens autores de violência.

Conforme Toneli e colaboradores (2010), a iniciativa de prestar atendimento para homens autores de violência tem como fundamento a ideia de que o sujeito pode reconhecer e responsabilizar-se pelos atos agressivos em que incidem ao assumir um compromisso com as formas hegemônicas de masculinidades, de modo que possam buscar alternativas existências não violentas e, via de consequência, promover o engajamento de homens pela equidade de gênero e ações para o fim da violência masculina em desfavor das mulheres.

Ainda segundo os mesmos autores, as iniciativas pioneiras foram desenvolvidas em países como Estados Unidos da América e Canadá, já nos anos de 1980, para em seguida serem replicadas em outros países. Sobre essas primeiras iniciativas, revelam:

Esses primeiros programas realizados se dedicavam majoritariamente ao controle da ira, usando técnicas cognitivas. Com o passar dos anos, percebeu-se que apenas o controle da ira era insuficiente, muitas vezes tendo efeitos contrários como o aumento da violência exercida e dominação masculina sob a mulher a partir dos novos conhecimentos adquiridos. Neste sentido, cada vez mais se recomenda os programas que trabalham questões de gênero em ambos os sujeitos, de modo mais subjetivo e buscam romper com ideologias tradicionais que justificam a violência exercida contra a mulher. (TONELI et al., 2010, p. 17-18)

Vale lembrar que a violência contra a mulher é um fenômeno específico em virtude da sua legitimidade ou, ao menos, tolerância social. Nossa cultura 
sexista e misógina reforça relações sociais desiguais que sustentam uma ideologia da supremacia e controle do homem sob a mulher, destacando características naturais para autorizá-los a punir aquilo que lhes parece desvio ou má conduta. Deste modo, não é raro encontrar homens justificando a violência que praticam contra suas companheiras a partir do uso de álcool e outras substâncias psicoativas, traição e ciúmes, impulsos incontroláveis ou, até mesmo, como autodefesa, alegando ser a violência que praticam resposta a um comportamento provocativo da própria mulher (OLIVEIRA, 2012), de maneira tal que a reflexão acerca das masculinidades - e dos padrões estereotipados de gênero de um modo geral - pode em muito contribuir para a redução dos casos de violência doméstica e familiar e, quiçá, para a concretização de uma sociedade mais justa e igualitária.

\section{UM BREVE DIAGNÓSTICO DA REALIDADE BRASILEIRA}

No Brasil, os programas e experiências de intervenção junto a homens autores de violência doméstica e familiar contra as mulheres datam do final da década de 1990, cabendo o pioneirismo ao Instituto Noos de Pesquisas Sistêmicas e Desenvolvimento de Redes Sociais, com sede na cidade do Rio de Janeiro, responsável pela elaboração de uma metodologia específica de grupos reflexivos de gênero e sua execução desde 1999. Segundo os seus idealizadores, a metodologia foi pensada a partir da realização de grupos de gênero com homens dos mais variados contextos - faixa etária, raça/etnia, religião, classe social etc. -, tendo como principal finalidade possibilitar a continência de estados afetivos e "a promoção de diálogos, tanto internos quanto externos, favorecendo a compreensão de como as situações de violência são construídas nas relações interpessoais e reforçadas no cotidiano pela cultura em que vivemos". (ACOSTA; ANDRADE FILHO; BRONZ, 2004, p. 15)

Com isso, o trabalho pretendia, dentre outras questões, desnaturalizar a conduta violenta e transformar os padrões da masculinidade hegemônica; promover a responsabilização de homens autores de violência intrafamiliar e de gênero; atuar no âmbito da prevenção; contribuir para a construção de uma rede de atenção para homens autores de violência de gênero e, concomitantemente, reforçar as redes de atenção para as mulheres; e avaliar o impacto da violência intrafamiliar e de gênero, a fim de favorecer a elaboração e implementação de políticas públicas. (ACOSTA; ANDRADE FILHO; BRONZ, 2004)

Nos anos seguintes, outras poucas iniciativas são conhecidas, a exemplo do programa municipal da Prefeitura de Blumenau (Santa Catarina) e o Programa Andros do Instituto Albam, localizado em Belo Horizonte (Minas Gerais), 
desenvolvido em parceria com o Poder Judiciário e a Secretaria de Defesa Social do Estado de Minas Gerais. (BEIRAS, 2014) Contudo, é a partir de 2006, com a promulgação da Lei Maria da Penha, que esses programas são ampliados. Conforme redação de seu artigo 35, inciso $V$, a lei estabelece a criação dos referidos serviços e, ainda, em seu artigo 45, assegura que, "nos casos de violência doméstica contra a mulher, o juiz poderá determinar o comparecimento obrigatório do agressor a programas de recuperação e reeducação", garantindo, assim, que essas iniciativas sejam vislumbradas.

Em esforço recente, Adriano Beiras (2014) buscou mapear os serviços e programas desenvolvidos em território nacional. O pesquisador conseguiu analisar 19 em um universo de 25 programas desse tipo localizados em todo o território nacional, já que alguns se encontravam inativos temporariamente ou permanentemente. Os serviços são, em sua maioria, vinculados a órgãos governamentais e estão concentrados prioritariamente no eixo sul-sudeste e centro-oeste do país. Na região norte, apenas um serviço foi mapeado (no estado do Acre), enquanto no nordeste nenhum foi localizado. Os resultados apresentados na pesquisa de Beiras (2014) apontam ainda para outras questões de suma importância no que diz respeito à implementação desses serviços no Brasil, dentre as quais duas merecem destaque.

Primeiramente, não se tem construído um desenho metodológico próprio para se pensar esse tipo de intervenção no Brasil. As metodologias empregadas são variadas, mas, em geral, desenvolvem-se a partir de encontros semanais e em formato de dinâmicas e exposições grupais explicativas, bem como conversas reflexivas tomando por base alguns disparadores como textos de jornais, piadas, vídeos etc. As discussões são travadas sobre temas variados, mas com forte apelo às questões de gênero, construção das masculinidades e violência contra a mulher. (BEIRAS, 2014) Ou seja, não se tem clareza nem uniformização dos métodos empregados.

A outra grande questão, decerto, diz respeito à dificuldade de recursos contínuos para a construção e manutenção das iniciativas, agravada pela falta de uma política nacional específica relacionada ao trabalho com homens autores de violência, fazendo com que muitas iniciativas sejam pontuais e localizadas.

Apesar de haver uma política nacional de enfrentamento à violência contra mulheres [...] esta apenas menciona a necessidade do trabalho com os homens considerados agressores e também ainda é muito recente, considerando que data de 2011. Seria possível afirmar que há a falta de um aprofundamento e criação de diretrizes específicas a estes serviços com homens, sempre em consonância com os demais serviços indicados na política nacional já citada. (BEIRAS, 2014, p. 60) 
Com essas questões em aberto, a ampla implementação dos serviços de responsabilização e educação para homens autores de violência doméstica e familiar contra as mulheres está longe de ser um consenso no Brasil, o que, como visto, não tem impedido a execução de algumas experiências. Nossa preocupação, então, concentra-se, a partir deste momento, no contexto local, buscando mapear as ações desenvolvidas no interior do Estado da Bahia e as repercussões que têm provocado entre os/as gestores/as de políticas públicas.

\section{AS AÇÕES DESENVOLVIDAS NO INTERIOR DA BAHIA}

Lançado em 2007, o Pacto Nacional pelo Enfrentamento à Violência contra a Mulher consiste em um acordo federativo firmado pelo Governo Federal e pelos governos dos estados e municípios do país, visando o planejamento de ações que consolidem a Política Nacional pelo Enfrentamento à Violência contra a Mulher por intermédio da implementação de políticas públicas. Com isso, busca-se promover a prevenção e garantir assistência e acesso aos direitos das mulheres em situação de violência. (BRASIL, 2011a)

Em 2011, portanto, quatro anos após a implementação do referido pacto, verificou-se a necessidade de manutenção, ampliação e fortalecimento das propostas consubstanciadas no documento, articulando-as em cinco eixos fundamentais: garantia da aplicabilidade da Lei Maria da Penha; ampliação e fortalecimento da rede de serviços para mulheres em situação de violência; garantia da segurança cidadã e acesso à justiça; garantia dos direitos sexuais e reprodutivos, enfrentamento à exploração sexual e ao tráfico de mulheres; e garantia da autonomia das mulheres em situação de violência e ampliação de seus direitos. (BRASIL, 2011a)

Como uma das estratégias de monitoramento e avaliação do Pacto Nacional pelo Enfrentamento à Violência contra a Mulher, compete aos estados desenvolver o Planejamento Integral Básico (PIB), no qual se promova um diagnóstico sobre o processo das conferências e políticas para as mulheres, bem como uma proposta de planejamento e orçamento para a implementação do Pacto de acordo com o Plano Plurianual dos Estados.

$\mathrm{Na}$ Bahia, cujo território encontra-se dividido em 417 municípios, 116 assinaram o Pacto pelo Enfrentamento à Violência contra a Mulher. Para a construção do PIB, mais de uma dezena de pesquisadores (as) foram contratados (as) no intuito de percorrer todos os municípios pactuantes para realizar entrevistas semiestruturadas e semidiretivas com os (as) gestores (as) responsáveis pela execução das políticas públicas para as mulheres e pelos mecanismos de enfrentamento à violência doméstica e familiar. 
Neste trabalho, contudo, conseguimos alcançar apenas os dados produzidos a partir das entrevistas realizadas em 19 municípios, das quais estivemos diretamente envolvidos em quatro (Feira de Santana, Valença, Taperoá e Lauro de Freitas). A instituição responsável pela execução do planejamento cedeu ainda acesso às transcrições de entrevistas desenvolvidas por outros/as colegas nos seguintes municípios: Camaçari, Cruz das Almas, Governador Mangabeiras, Itabuna, Itaguaçu, Irecê, Juazeiro, Maragogipe, Salvador, São Francisco do Conde, São Sebastião do Passé, Santo Amaro, Saubara, Simões Filho, e Souto Soares.

Cumpre destacar que, não obstante a implementação dos serviços de responsabilização e educação para homens autores de violência não constar explicitamente entre os objetivos do pacto, conseguimos incluir questões sobre o tema no roteiro de entrevista empregado na pesquisa, que davam conta basicamente da existência de programas/ações, aspectos metodológicos e fontes financiadoras. Ademais, parte significativa desses municípios dispõem de apenas um mecanismo de execução de políticas públicas para as mulheres ou de enfrentamento à violência doméstica e familiar, de modo que utilizaremos códigos para a identificação das falas de nossos (as) interlocutores (as), sem proceder com a associação ao município em que trabalham, como estratégia para garantir o anonimato.

Ressaltamos ainda que essas falas estão permeadas de nuances e ambiguidades, sobretudo pela vinculação institucional desses sujeitos, que faz com que ora se preocupem em reproduzir um discurso oficial, ora evidenciem suas percepções mais íntimas. Logo, não podemos promover leituras homogeneizadoras das instituições que representam, pois embora possuam um objetivo em comum - o enfrentamento à violência contra a mulher - atuam a partir de dinâmicas e desafios específicos.

Os dados produzidos corroboram e atualizam as informações encontradas na pesquisa de Beiras (2014), no sentido de que não há em todo o território estadual nenhum serviço ou programa específico para homens autores de violência doméstica e familiar contra a mulher. No entanto, em alguns municípios, ações pontuais são desenvolvidas com os homens, geralmente palestras e rodas de conversas com homens produzidas por Organizações Não Governamentais (ONG) que atuam nas questões dos direitos humanos e/ou profissionais que integram a própria rede de enfrentamento à violência doméstica e familiar.

Teve palestras voltadas para homens, que agora mesmo nos 16 dias de ativismo tem sempre a campanha do laço branco, que é a campanha do homem que diz não à violência contra a mulher. A gente sempre teve esse movimento. (EO1) 
Uma vez nós fizemos até uma palestra com as mulheres e compareceram até muitos homens, sei que no fim surgiu aquela discussão. Surgiu uma discussão terrivel, nessa coisa que nós fizemos lá, porque teve alguns homens, a palestra saiu em defesa da mulher e foi uma confusão. No fim, eu tive até que intervir nas discussões, mas foi bom. (E02)

Em dois municípios pesquisados, as entrevistadas relataram que essas ações estão sendo encabeçadas pelo Centro de Referência Especializado de Assistência Social (Creas), enquanto outros dois, que dispõem de Varas Especializadas em Violência Doméstica e Familiar, o Poder Judiciário tem desenvolvido ações a partir de suas equipes multidisciplinares em um caso e em parceria com grupos universitários em outro. Neste sentido:

Então, eu já participei de algumas formações para homens aqui no CREAS, aqui embaixo. Palestras e tal. Mas, hoje em dia a gente não pode está mais participado. A nossa equipe, por norma técnica, não pode ter contato com agressor. Então, isso provavelmente vai ficar a cargo do CREAS. (E03)

[A] gerente de proteção social especial e que gerencia o CREAS, ela disse que - CREAS está aí para ofertar esse serviço, mas a CEAPA, que é a instituição que encaminh a para a ressocialização não encaminha mais homens. (E04) Na vara de violência doméstica e familiar, com esse novo juiz, ele montou, ele implantou lá na vara um centro de atendimento psicossocial ao agressor. Então, esse agressor ele vai para a vara, lá tem uma sala específica e ele recebe algumas orientações, algumas informações acerca da violência contra a mulher, como isso acontece. (E05)

Percebe-se, portanto, que as investidas na atenção a homens autores de violência contra a mulher percebidas no estado da Bahia ainda são bastantes tímidas e consistem, basicamente, em ações pontuais, sem solução de continuidade, desenvolvidas por ONGs ou representantes de movimentos sociais. Ou seja, não há no estado uma política pública efetiva de atendimento a esses sujeitos, uma vez que as políticas públicas se caracterizam por serem ações perenes, com regulamentação do estado, quer seja na esfera municipal, estadual ou federal, proposta com a finalidade de atingir um bem coletivo.

Nos dizeres de Eduardo Appio (2006, p. 136), as políticas públicas devem ser entendidas como "instrumentos de execução de programas políticos baseados na intervenção estatal na sociedade com a finalidade de assegurar igualdade de oportunidades aos cidadãos", garantindo-lhes as condições materiais de uma existência digna. Ademais, via de regra, é o Poder Executivo, por meio do planejamento de suas estratégias de atuação, o responsável pela elaboração das políticas públicas, ainda que se verifique, nos últimos anos, uma tendência em buscar apoio nas atividades dos chamados "conselhos de gestão", que contam com a participação maciça de diversos segmentos sociais, como associações, movimentos sociais, ONGs etc., contribuindo de maneira significativa para o 
exame das prioridades do Estado na defesa dos direitos e garantias fundamentais dos (as) cidadãos (as).

Se não há uma política pública de atendimento a homens autores de violência contra a mulher consolidada no estado da Bahia, igualmente não há consenso na necessidade de desenvolvimento de ações nesse sentido. A fala de algumas de nossas interlocutoras evidencia a resistência a esse tipo de abordagem, destacando preocupações relevantes que, no fundo, dialogam sobre disputa de recursos públicos e questões metodológicas, como a formação dos profissionais envolvidos: Eu não conheço esse atendimento ainda, mas eu não sou muito favorável a esse atendimento, mesmo porque esses profissionais que tem lá, um psicólogo homem e uma assistente social, não é pelo fato de ser homem ou mulher, mas é pelo fato deles não terem recebido uma formação específica para trabalhar com essas questões de gênero e também da violência contra a mulher. (E05)

Já é tão difícil trabalhar só com a problematização da mulher com essa equipe mínima. Essa mesma equipe não pode atender o homem, de forma alguma. [...] já é dificil dizer a realidade com dados quantitativos de violência doméstica, dizer o que é que a gente precisa, imagina a gente dizer que precisa de..., entendeu? (E06)

Por outro lado, outros (as) gestores (as) demonstraram uma forte tendência ao reconhecimento da necessidade da criação desses serviços ou, ao menos, do acirramento do debate a fim de refletir sobre a adoção de estratégias, por vezes associando sua fala a uma demanda das próprias mulheres em situação de violência: [...] a gente sabe e a gente tem um projeto onde que a gente tem que investir principalmente no treinamento com os homens policiais, um treinamento com os homens nas ruas. Então, isso é uma coisa que a gente está fazendo, mas por enquanto só em sala de espera quando há presença deles. (E07)

Porque, na verdade, as mulheres que estão em situação de violência doméstica, a gente está quantificando também que muitas delas querem que os agressores se tratem, porque na verdade elas não querem separação e nem a gente está aqui para separar ninguém. A gente não orienta separação. A gente orienta o fortalecimento da mulher para ela enfrentar a situação que ela está vivendo. Mas, se ela decidir se separar, é uma questão pessoal dela. E já existe esse entendimento do município que a gente precisa fazer um trabalho para que a gente possa fazer um acompanhamento a esses agressores, para que eles se reestruturem, repense. Porque, na verdade, a mulher não quer deixar o marido. Ela gosta do marido. Ela quer ficar com o marido, ela não quer a situação que o marido se coloca de viver com ela. (E01)

A última fala deixa patente, inclusive, a dificuldade de romper com uma lógica privatista/familista que, ao negar o caráter público da violência contra a mulher, limitando-se a entender este como um fenômeno privado, pode, em muitos casos, impedir a ruptura com o ciclo da violência e reforçar a impuni- 
dade dos seus autores. Carmen Hein Campos (2015), ao pensar os principais obstáculos para a implementação da Lei Maria da Penha, destaca a resistência de operadores/as do direito em entender a proposta da nova lei e romper com tal lógica familista, o que, ante o exposto, poderíamos estender também para algumas gestoras de mecanismos de enfrentamento à violência contra a mulher.

Em situações extremas, a dificuldade de ruptura com a lógica familista aliada ao reconhecimento da necessidade e à ausência de um serviço/programa específico de atendimento a homens autores de violência tem feito com que as ações sejam desenvolvidas nos próprios mecanismos de atendimento a mulheres em situação de violência doméstica e familiar. Abaixo, colacionamos a fala da coordenadora de um Núcleo de Atendimento à Mulher (NAM) após ser questionada sobre a ocorrência de algum acompanhamento prestado a homem autor de violência pelo serviço em que atua:

Já, a advogada já. Nós fazemos visita, nós convidamos às vezes para vir aqui, para conversar não só com a advogada, com a assistente social. Às vezes com a psicóloga também. Eles frequentam muitas vezes a psicóloga, porque no momento que acontece alguma coisa, essa violência, não defendo essa hora o homem porque não existe defesa, mas tem coisas e tem casos que às vezes depois que ele conversa com a psicóloga, assistente social, a gente sente que há uma questão de mudança, né? É tanto que às vezes eles voltam, se unem de novo, que eu não sei se é certo, se é errado. (Eo2)

Ressalte-se que, conforme as normativas nacionais, os serviços especializados de atendimento à mulher são "aqueles que atendem exclusivamente a mulheres e que possuem expertise no tema da violência contra a mulher". (BRASIL, 2011b) Mesmo alegando o conhecimento da normativa, em outro município, a gestora revela o atendimento a homens no interior de um Núcleo de Atendimento à Mulher:

[...] a regra que a gente tem, do ministério, quando a gente implantou 0 NAM, é que ele era atendimento especializado e voltado só para a mulher. Mas, eu digo assim, o nosso objetivo não é o de destruir famílias. [...] Então, a gente precisa ouvir as duas partes. Então, a gente passa às vezes para um divórcio, um acordo. Aí a advogada convida os dois, ouve um, ouve o outro, e faz um acordo. Os dois assinam, levam no fórum, homologa. Entendeu? Que é a conciliação. É conciliado onde os dois querem a separação. [...] a gente percebeu essa demanda. Porque você ir com um divórcio para ofórum, para a justiça, para esperar aquela demora toda, de repente o homem vai matar a mulher. Então, o que é que a gente pode fazer? Botar os dois sentados, porque às vezes é a forma de diálogo. Porque a gente já teve família que o homem hoje, graças a Deus, 6-5 anos é um homem maravilhoso. Segundo ela, que deixou de agredir, que foi um momento relapso da vida que ele agrediu ela. Aí a gente chamou ele, convidou e hoje ele reconstruiu a família dele, construiu outra visão. (Eo8) 
Até mesmo as diretrizes gerais dos serviços de responsabilização e educação do homem autor de violência apontam que, "sob nenhuma hipótese, o equipamento poderá funcionar nos serviços especializados de atendimento à mulher" (BRASIL, 2011b), em flagrante preocupação com a não descaracterização desses espaços que, ao serem frequentados pelos algozes, pode afastar as mulheres em situação de violência ou mesmo revitimizá-las.

\section{CONSIDERAÇÕES FINAIS}

Como visto, em nossa sociedade, experimentamos processos de socialização e sociabilidade que valorizam os constructos simbolicamente associados ao masculino e desdenha, recrimina ou simplesmente diminui aquilo que se associa ao feminino, seja ele exercido por mulheres ou homens, de modo a influenciar a construção de um padrão cultural que perpetua a violência de gênero e, mais especificamente, a violência contra a mulher. Deste modo, consideramos que é necessário apostar numa ressignificação simbólica do masculino em nossa sociedade, inclusive como estratégia de enfrentamento ao fenômeno da violência doméstica e familiar.

Os serviços de responsabilização e educação para homens autores de violência, ao apostar em atividades capazes de promover nesses sujeitos a reflexão sobre os padrões estereotipados de masculinidade e alternativas não violentas para a resolução dos seus conflitos interpessoais, podem cumprir um papel deveras interessante. Neste sentido, alguns estudos apontam para baixos índices de reincidência no comportamento violente entre homens que participaram integralmente dos programas, além de outros impactos positivos, ${ }^{4}$ sinalizando para o potencial transformador dessas intervenções.

Contudo, para que esses serviços alcancem as finalidades a que se destinam e se consolidem enquanto política pública de enfrentamento à violência contra a mulher, um longo caminho ainda parece ter que ser percorrido. Pois, é preciso investir, sobretudo, em reflexões críticas sobre o desenho metodológico a ser empregado e na consolidação de uma política que lhe assegure recursos contínuos.

Quando pensamos o contexto baiano, percebemos nitidamente como essas lacunas têm promovido a adoção de estratégias muitas vezes equivocadas, em total afronta ao que já se convencionou política e teoricamente sobre o assunto, e que, ainda que bem-intencionadas, podem provocar um efeito contrário ao enfrentamento da violência doméstica e familiar contra a mulher e o descré-

\footnotetext{
Ver, por exemplo, Andrade e Barbosa (2008) e Teixeira e Maia (2011).
} 
dito do serviços de responsabilização e educação como um mecanismo viável e necessário para se pensar a responsabilização dos homens autores de violência.

\section{REFERÊNCIAS}

ACOSTA, F.; ANDRADE FILHO, A.; BRONZ, A. Conversas homem a homem: grupo reflexivo de gênero. Rio de Janeiro: Instituto NOOS, 2004. (Homens e violência do gênero, 3).

ANDRADE, L. F.; BARBOSA, S. F. A Lei Maria da Penha e a implementação do grupo de reflexão para homens autores de violência contra mulheres em São Paulo. In: FAZENDO GÊNERO: CORPO, VIOLÊNCIA E PODER, 8., 2008, Florianópolis. Anais eletrônicos [...] Florianópolis: UFSC, 2008. Disponível em: http://www.fazendogenero. ufsc.br/8/sts/ST42/Andrade-Barbosa_42.pdf. Acesso em: 15 abr. 2016.

APPIO, E. F. O controle judicial das políticas públicas no Brasil. 2006. 473 f. Tese (Doutorado em Direito) - Universidade Federal de Santa Catarina, Florianópolis, 2006.

BARDIN, L. Análise de conteúdo. Lisboa: Edições 70, 1977.

BEIRAS, A. Relatório mapeamento de serviços de atenção grupal a homens autores de violência contra mulheres no contexto brasileiro. Rio de Janeiro: Instituto NOOS, 2014.

BRASIL. Lei n. 9.099, de 26 de setembro de 1995. Dispõe sobre os Juizados Especiais Cíveis e Criminais e dá outras providências. Diário Oficial [da] República Federativa do Brasil, Poder Executivo, Brasília, DF, 27 set. 1995. BRASIL. Lei n. 11.340. Diário Oficial [da] República Federativa do Brasil, Poder Executivo, Brasília, DF, 08 ago. 2006.

BRASIL. Secretaria de Políticas para Mulheres. Pacto nacional pelo enfrentamento à violência contra a mulher. Brasília, DF, 2011 .

BRASIL. Secretaria Nacional de Enfrentamento à Violência contra as Mulheres. Rede de endrentamento à violência contra as mulheres. Brasília, DF, 2011b. (Coleção Enfrentamento à violência contra as mulheres).

CAMPOS, C. H. de. A CPMI da violência contra a mulher e a implementação da Lei Maria da Penha. Revista Estudos Feministas, Florianópolis, v. 23, n. 2, p. 519-351, maio/ago. 2015.

CONNELL, R. W.; MESSERSCHMIDT, J. W. Masculinidade hegemônica: repensando o conceito. Estudos Feministas, Florianópolis, v. 21, n. 1, p. 241-282, jan./abr. 2013.

COSTA, A. A. A. O movimento feminista no Brasil: dinâmicas de uma intervenção política. Gênero, Niterói, v. 5, n. 2, p. 1-20, 2005.

DINIZ, S. G. Violência contra a mulher: estratégias e respostas do movimento feminista no Brasil (1980-2005). In: DINIZ, C. S. G.; SILVEIRA, L. P. da; MIRIM, L. A. L. (Org.). Vinte e cinco anos de respostas brasileiras em violência contra as mulheres no Brasil (1980-2005): alcances e limites. São Paulo: Coletivo Feminista Sexualidade e Saúde, 2006. p. 78-139.

OLIVEIRA, Anderson Eduardo Carvalho de. Atendimento a homens autores de violência contra a mulher: lacunas, desafios e perspectivas. 2012. 122 f. Dissertação (Mestrado 
em Estudos Interdisciplinares sobre Mulheres, Gênero e Feminismo) - Faculdade de Filosofia e Ciências Humanas, Universidade Federal da Bahia, Salvador, 2012.

SCOTT, J. Gênero: uma categoria útil de análise histórica. Educação \& Realidade, Porto Alegre, v. 20, n. 2, p. 71-99, jul./dez. 1995.

TEIXEIRA, M. S.; MAIA, M. Avaliação do projeto paz em casa, paz no mundo a partir dos seus beneficiários. Rio de Janeiro: NOOS, 2011. Disponível em:http://www.noos.org.br/ userfiles/avalia\%C3\%A7\%C3\%A30\%20do\%20projeto\%2opaz\%20em\%2ocasa.pdf. Acesso em: 15 abr. 2016.

TONELI, M. J. F. et al. (org.). Atendimento a homens autores de violência contra as mulheres: experiências latino americanas. Florianópolis: UFSC/CFH/NUPPE, 2010. 